\title{
The Impact of Coalition Offensive Operations on the Iraqi Insurgency
}

\author{
Matthew A. Hanson * \\ College of William and Mary
}

Martin B. Schmidt

College of William and Mary

\section{College of William and Mary \\ Department of Economics \\ Working Paper Number 56}

September 2007

\footnotetext{
* Hanson is an undergraduate double majoring in Economics and Mathematics. Schmidt is an Associate Professor in the Department of Economics. We wish to thank, without implicating, David Jaeger, Robert Hicks, Carl Moody, Till Schrieber, James and Peggy Hanson, and Jeff Jaworski for helpful discussions. We would also like to thank all participants at the National Bureau of Economic Research 2007 Summer Institute Program on the Economics of National Security, particularly Steven Davis, Alex Gelber, Martin Feldstein, Jesse Shapiro, and John Warner for their helpful comments and suggestions. The usual disclaimer applies.
} 
COLLEGE OF WILLIAM AND MARY

DEPARTMENT OF ECONOMICS

WORKING PAPER \# 56

September 2007

\title{
The Impact of Coalition Offensive Operations on the Iraqi Insurgency
}

\begin{abstract}
Coalition offensive operations in Iraq seek to disrupt insurgents and their networks, but may also act as a recruitment tool for the insurgency. We use data from Coalition press releases and casualty reports to assess the total impact of these operations. We find that two additional offensive operations come at a future cost of an additional Coalition soldier's life. The evidence suggests that rather than diminishing the insurgents' appetite to wage counterattacks, these operations may act as a recruitment tool for the insurgency. We further find that while the insurgents change their level of operations in response to the Coalition, the Coalition does not react to the insurgents.
\end{abstract}

JEL Codes: C32, D74, H56

Keywords: $\quad$ Proactive Countermeasures, Iraq War, Terrorism, Vector Autoregression, Granger Causality

Matthew A. Hanson

Department of Economics

College of William and Mary

Williamsburg, VA 23187-8795

mahans@wm.edu
Martin B. Schmidt

Department of Economics

College of William and Mary

Williamsburg, VA 23187-8795

mbschm@wm.edu 
"As U.S. tactics get more

aggressive, more troops die"

Baltimore Sun - May 30th, 2007

\section{Introduction}

Since the end of major combat operations in Iraq on May 1, 2003, the multinational force in Iraq (MNF-I or Coalition force) has been involved in a difficult occupation. The occupation has been violently opposed by a collection of insurgent groups including Shia militias, Sunni Islamists, Ba'athists from Saddam Hussein's regime, nationalists, and foreign fighters linked to groups such as al-Qaeda. The significant level of popular support for these insurgent groups and their diverse goals and methods has been a major challenge in the efforts of the Coalition to provide basic security and political or economic benefits to the Iraqi people. ${ }^{1}$

Much Coalition activity has focused on military solutions to the problem of the insurgency. While the political, economic, and social domains to the fight against the insurgency in Iraq have not been ignored, they have not until recently occupied a prominent place among the U.S. military leadership that has largely decided the methods of counterinsurgency. ${ }^{2}$ Rather Coalition activities have largely focused on offensive military operations. Broadly defined, offensive operations are military operations which disrupt enemy coherence, secure or seize terrain, deny the enemy resources, fix the enemy, or gain information. ${ }^{3}$ Because our focus is counterinsurgency, we focus on the more limited subset of cordon and search, cordon and knock, patrols, raids, the finding of weapons caches, and other similar actions, excluding major offensives similar to traditional military operations.

Offensive counterinsurgency operations provide benefits through disruption to the insurgent net-

\footnotetext{
${ }^{1}$ A March 2007 ABC News Poll found that more than half of all Iraqis supported attacks on Coalition forces http : //abcnews.go.com/images/US/1033aIraqpoll.pdf. That number was $17 \%$ in early 2004 .

${ }^{2}$ As an example of the recent shift in focus, General David H. Petraeus, a strong advocate of counterinsurgency theory rather than traditional military operations, e.g. Petraeus and Amos (2006), was recently appointed the head of MNF-I.

${ }^{3}$ See FM 3-0: Operations (2001). Note that we use offensive operations to refer to our limited subset rather than the military definition. We also use the synonymous terms proactive operations and proactive countermeasures.
} 
work - insurgents are captured or killed, weapon caches are found, and an increased probability of capture or death may reduce the ability of the insurgency to recruit followers. However, these operations may anger the civilian populace. The homes and property of noncombatants are often damaged. There are frequent misunderstandings, leading to accidental civilian casualties due to the necessary force protection measures of the counterinsurgents. Furthermore, the mere presence of the counterinsurgents - seen as an occupying power by the overwhelming majority of Iraqis - may inflame the populace. ${ }^{4}$

Individually or in totality, these may lead to increased recruitment into insurgent networks. The role of recruitment in support of insurgency has been detailed in a number of books and articles. As an example, Hashim (2006) describes the U.S. counterinsurgency as "uniformly muscular, its weapon of choice the blunt military instrument" and provides the following quote from an Iraqi:

In November 2003 Operation Iron Hammer...temporarily succeeded in reducing the number of daily attacks. However, it also created fresh enemies because of the rough treatment allegedly meted out to the people who were caught up in the sweep. One Iraqi woman said: 'I used to feel sympathy for the soldiers. They looked young and were away from their families. But not anymore. If the people had some mercy for the Americans before, they don't anymore. God bless the resistance. ${ }^{5}$

This paper uses the vector autoregression (VAR) methodology to assess the impact of an offensive operation. While a formal estimate of the costs and benefits of counterinsurgency operations is beyond the scope of the present piece, we do examine one aspect of these actions: the insurgents' response. Specifically we use the public accounts of Coalition force offensive operations in Iraq and measure the insurgents' responses through the public accounts of Coalition soldiers killed in action.

\footnotetext{
${ }^{4}$ In February 2004, a ABC News poll found that 51 percent of Iraqis opposed the presence of U.S. forces on their soil. By March of 2007 that number has jumped to 78 percent - http ://abcnews.go.com/images/US/1033aIraqpoll.pdf.

${ }^{5}$ The Iraqi woman's quote is reported in Blandford (1 December 2003). Hashim (2006, p. 322-340) provides an extensive discussion of the recruitment gains to the insurgency from Coalition offensive operations.
} 
In the end, we find that two additional Coalition offensive operations come at a future cost of an additional Coalition soldier's life.

The plan of the paper is as follows. First, section 2 reviews the relevant economic literature. Section 3 describes the incorporated data for both the Coalition forces offensive military actions and the insurgents' response. In section 4, we describe the basic econometric methodology to investigate the insurgents' response and report the empirical results from analyzing the time-series data. We pay specific attention to the data's impulse response functions. Section 5 provides a short discussion of the relevant policy considerations, while section 6 concludes the paper.

\section{Review of Literature}

Insurgency and counterinsurgency behavior lend themselves easily to economic analysis, e.g. Schelling (1960). Leites and Wolf (1970), for example, presents a detailed analysis of the motivations and actions of insurgents and counterinsurgents based on economic theory. ${ }^{6}$ More recently, Enders and Sandler (2006) combines economic methods and political analysis in rational actor and game theoretic models to examine both domestic and transnational terrorism from a political economy point of view. ${ }^{7}$

Empirical economic analysis of terrorism began with Landes (1978) who found that airport screening, federal air marshals, and a bilateral extradition treaty with Cuba (all of which increase the probability of capture) brought the 1961-1972 epidemic of airplane hijacking to a virtual halt by 1973. Along the lines of the present piece, Enders, Sandler and Cauley (1991) used the VAR approach, as well as its associated variance decomposition, to demonstrate that terrorism by Basque separatists had the effect of decreasing tourism in Spain. Cauley and Im (1988) used interrupted time series analysis to analyze the substitution effect produced from changes in the cost of committing

\footnotetext{
${ }^{6}$ While the original report was focused on the war in Vietnam, it remains useful for more recent conflicts.

${ }^{7}$ Enders and Sandler (2006) also provides an excellent summary of the empirical work that has been done on terrorism.
} 
acts of terrorism from counterterrorism efforts. Enders and Sandler (1993) combined the VAR and interrupted time series approaches to assess the total costs and benefits of counterterrorism policies when considering different terrorist actions as substitute or complementary goods. ${ }^{8}$

The Enders and Sandler (1993) study is particularly relevant to the present analysis. Using data from 1968-1988, Enders and Sandler found that metal detectors and fortification of U.S. embassies (defensive actions) were the most effective antiterrorism policies undertaken, but that these measures had the effect of increasing the probability of other types of attacks such as hostage-taking or assassinations. Interestingly for the current analysis, Enders and Sandler determined that the 1986 U.S. attack on Libya (considered an offensive or proactive action) in retaliation for the bombing of the LaBelle Discotheque in West Berlin had a short-run effect of increasing terrorism against the U.S. and United Kingdom. However, they found no long-term impact.

More recent studies have focused on the Palestinian-Israeli conflict, e.g., Jaeger and Paserman (2006a) and Jaeger and Paserman (2006b). Jaeger and Paserman (2006a), for example, investigate the responses of Palestinian forces to fatal Israeli attacks and vice versa. Using Granger causality tests, they find that Israeli forces respond to Palestinian lethal attacks with lethal attacks of their own. The converse is, however, not true. They conclude that little evidence exists to support the popular notion of the two forces being engaged in 'tit-for-tat' warfare. Benmelech and Berrebi (2007) also examined the Palestinian-Israeli conflict and found that Palestinian suicide bombers with higher human capital levels (age and experience) are assigned to higher-value targets and are more successful in their attacks.

\footnotetext{
${ }^{8}$ Sandler and Enders (2002) provided an excellent survey of the economic techniques used in the analysis of terrorism.
} 


\section{Data}

In March of 2003, the United States and its allies invaded Iraq in order to remove Saddam Hussein from power. ${ }^{9}$ By mid-April, Coalition forces had taken Baghdad and effectively ended Saddam Hussein's 24-year totalitarian rule. Major combat operations were declared over on May 1st, 2003.

However, the post-regime change period has not been smooth. While the total number of Coalition personnel killed in action during major combat operations (those prior to May 1st, 2003) was 108, the Coalition forces have lost more than 3000 of their soldiers since. ${ }^{10}$ Moreover, the characteristics of the conflict have been very different since the end of major combat operations. The initial stage of combat involved a traditional campaign involving the forces of organized, uniformed militaries. The secondary stage has been fought between the Coalition forces and an insurgency primarily carrying out improvised explosive device (IED) or small arms hit-and-run attacks with the intent of reducing the will of the Coalition nations to continue their mission. It is the secondary stage that we focus on in this paper.

We require data on the Coalition's offensive operations and the insurgents' response. As our measure of Coalition offensive operations we use daily counts of reported Coalition operations meeting certain criteria. For our measure of the insurgency's response we use daily counts of Coalition soldiers killed in action. We describe these in turn.

\subsection{Coalition Offensive Operations}

The data for the Coalition offensive operations were derived from press releases from U.S. Central Command (CENTCOM). ${ }^{11}$ The mission of CENTCOM is:

\footnotetext{
${ }^{9}$ The nations contributing forces to the initial invasion were the United States, United Kingdom, Australia, Poland, and Denmark. Thirty-three nations have provided troops in the subsequent occupation. However the United States has and continues to provide over 90\% of Coalition forces - $h t t p$ :

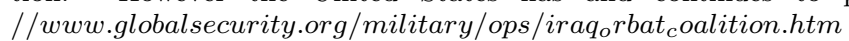

${ }^{10}$ The total reflects casualties as of May 31st, 2007.

${ }^{11}$ The CENTCOM releases were obtained from http://www.centcom.mil. We used a Perl script to download and parse all press releases issued prior to December 1st, 2006.
} 
U.S. Central Command conducts operations to attack, disrupt and defeat terrorism, deter and defeat adversaries, deny access to WMD, assure regional access, strengthen regional stability, build the self-reliance of partner nations security forces, and protect the vital interests of the United States within the area of responsibility.

The CENTCOM press releases are therefore released to describe actions taken and consequences incurred in support of this mission.

The CENTCOM press releases are available from the beginning of Operation Iraqi Freedom in March 2003. ${ }^{12}$ During this period CENTCOM has released over 4000 press releases for both Operation Iraqi Freedom and Operation Enduring Freedom in Afghanistan. We, however, only consider press releases with reference to actions taken in Iraq.

Our data for offensive operations were generated by flagging a press release as representing an operation whenever it contained any member of a set of words. Specifically, the words included were raid, cordon, search, cache, nab, capture, and detain (but not detainee). ${ }^{13}$ Our daily count (which we label OPS) is therefore the number of flagged press releases issued for each day.

One drawback with the operations data is that some of the CENTCOM press releases contain reports of multiple operations, while others contain reports of a single operation. While we might correct for this by using the actual word counts, this would impose the restriction that all word uses indicate operations of the same scale. This raises a second drawback to our operations data: the reports generally do not report the operation's scale or scope. Specifically, weapons and equipment found are not reported consistently and the qualitative value of detainees may differ considerably from the number of people detained.

\footnotetext{
${ }^{12}$ We also incorporated a second source - press releases from the Multinational Force-Iraq (MNF-I) website. This data yielded virtually the same results. However, this data only started in June of 2005, while the CENTCOM releases are available from the beginning of the war.

${ }^{13}$ Since the MNF-I releases are more detailed and thus use a wider variety of terminology, it was necessary to include more terms in order to minimize measurement error - these were patrol, discover, find, arrest, suspect, uncover, operation, offensive, seize, net, kill, and insurgents killed.
} 
Rather than imposing the restriction that all operations are of the same scale or trying to correct this in an ad hoc manner, we allow the military to sort the data out in its issuance of press releases. Specifically, we assume that when multiple operations are reported within a press release these operations were correspondingly small. Therefore, press releases containing multiple flags or a single occurrence both count as a single offensive operation.

Both for operational security and because there are simply too many to report, not all operations are reported in the press releases. However, the usefulness of the data as proxy variables is justified if one assumes that the Coalition press offices seek to accurately report what is going on in Iraq through representative press releases, in which case the omitted operations are drawn randomly across success, type and time. If however the Coalition press offices are seeking to put a positive spin on operations, the press releases will underestimate the true number of offensive operations, in which case our estimates will likely overestimate the impact of operations on casualties. ${ }^{14}$

Along similar lines, CENTCOM is also not likely to report all operations in which nothing is discovered. Therefore, our measure would underreport the true number of offensive operations. However if one assumes that recruitment is a function of operation significance, i.e., the more significant the offensive operation the more likely recruitment, the inclusion of these events would mute the true impact of operations on casualties and therefore underestimate the true impact of operations on casualties. ${ }^{15}$

Finally, our data uses the date of the press release issuance which is, for operational security reasons, never in advance of an operation. While some press releases are released as quickly as one day after the operation has been underway, most press releases are issued after the operation is complete. Also, most press releases are not for major, named operations, but for small operations

\footnotetext{
${ }^{14}$ The impact on the estimated standard errors is less clear. If the number of unreported operations differs systematically from those which are reported than this may change the standard errors in either direction. If, however, the behavior of the unreported follows those that are reported than the standard errors would be similar.

${ }^{15}$ It would seem reasonable to argue that actual reporting falls somewhere between a perfectly representative sample and only reporting the operations they are most proud of, i.e. the ones with the biggest benefits.
} 


\begin{tabular}{|l|l|l|l|}
\hline Series & $\boldsymbol{t}$ & Mean & Std. Dev. \\
\hline \hline Operations & 1351 & 2.200 & 2.418 \\
\hline Casualties & 1351 & 1.722 & 2.2328 \\
\hline
\end{tabular}

Table 1: Summary Statistics for Daily Counts, 03/28/03 - 12/01/06.

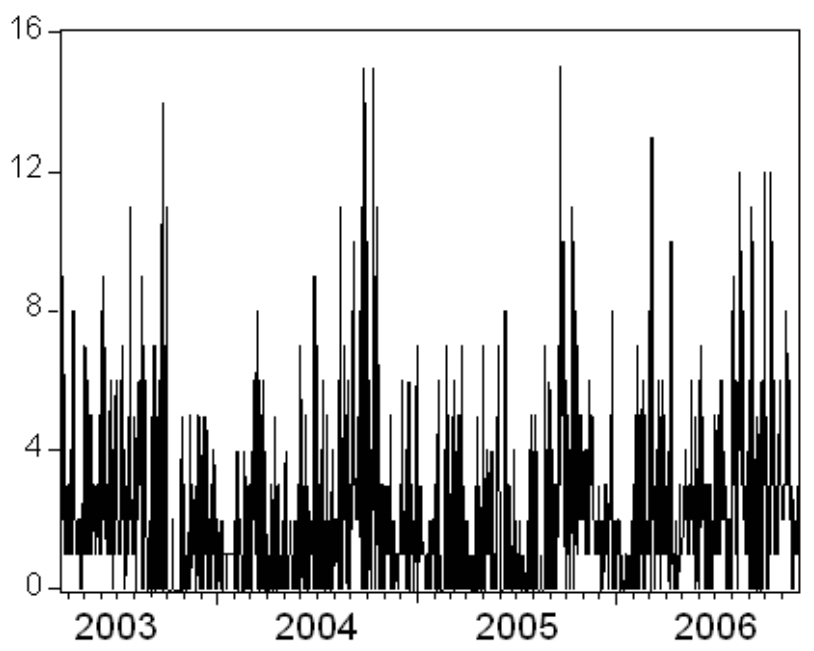

Figure 1: Coalition Operations, Daily (CENTCOM)

lasting only a matter of hours. Since most of these operations are conducted at night (and may therefore arbitrarily fall on one side of midnight), we can in any case expect that measurement error does not allow us to pin down the date closer than one day of accuracy. ${ }^{16}$

Figure 1 reports the daily operation data values. Cursory examination of the figure suggests a large amount of variability in Coalition operations. These are likely an outgrowth of the various levels a conflict is fought on - there are occasions where the military ramps up operations in order to accomplish a goal. ${ }^{17}$ On other occasions a lower level may be desired. Summary statistics for the series are presented in Table 1.

\footnotetext{
${ }^{16}$ This is likely less of a concern with the use of aggregated data. See next section.

${ }^{17}$ For example, in October of 2005 , there is an increase in operations due to a national referendum on the new constitution.
} 


\subsection{Coalition Causalities}

The data for Coalition casualties represents what is reputed to be a complete listing of all U.S. soldiers killed in action. In an attempt to reduce measurement error, only deaths due to hostile action were considered. These cases include improvised explosive device (IED) attacks, small arms fire, helicopter crashes due to hostile fire (not including mechanical failure), and other similar causes. These data are maintained by volunteers at the website icasualties.org and are based on U.S. Department of Defense casualty reports. ${ }^{18}$ The volunteers at icasualties.org "... endeavor to provide not just a list of names but a resource detailing when, where and how fatalities occurred." ${ }^{19}$ As we desire to reference the insurgents response we require an accurate notation of time and cause and these details are provided by icasualties.org. ${ }^{20}$

Figure 2 reports the Coalition casualty data in a time series we label KIA. As with the earlier operations data, the casualties data also reflects a good deal of variability. Most prominent are the spikes in April and November of 2004, corresponding to Operation Vigilant Resolve and Operation Al-Fajr - battles conducted to clear the city of Fallujah of insurgents. ${ }^{21}$ Summary statistics for the series are presented in Table 1.

We assume that the umber of Coalition casualties may be described as follows:

$$
K I A=f(C, I, P[\text { Contact } \mid C, I], E[\text { Casualties } \mid \text { Contact }])
$$

where $C$ denotes Coalition operations, $I$ denotes insurgent activities, and Contact refers to

\footnotetext{
${ }^{18}$ We use the term casualty as a synonym for killed in action, differing from the military's use of the term casualty to refer to both soldiers killed and wounded in action.

${ }^{19} \mathrm{http}: / /$ icasualties.org/oif/Methodology.aspx

${ }^{20}$ It is possible that some measurement error exists from ambiguity in whether an incident is considered hostile or not. For example, casualties due to a vehicle that crashes while maneuvering to avoid enemy fires may be reported as non-hostile when one might argue the crash was due to hostile fire. It is impossible to correct or estimate the exact magnitude of this measurement error, but it is believed to be small.

${ }^{21}$ These battles are excluded (primarily by selection of sample size) as outliers due to their dissimilarity to the rest of the campaign against the insurgency. The battles of Fallujah bore more resemblance to a military-on-military urban conflict than to a counterinsurgency campaign (also explaining why there are not corresponding spikes in the operations series at the time). However, inclusion of these battles, with corresponding dummy variables in the casualties time series, does not change the qualitative conclusions of the paper.
} 


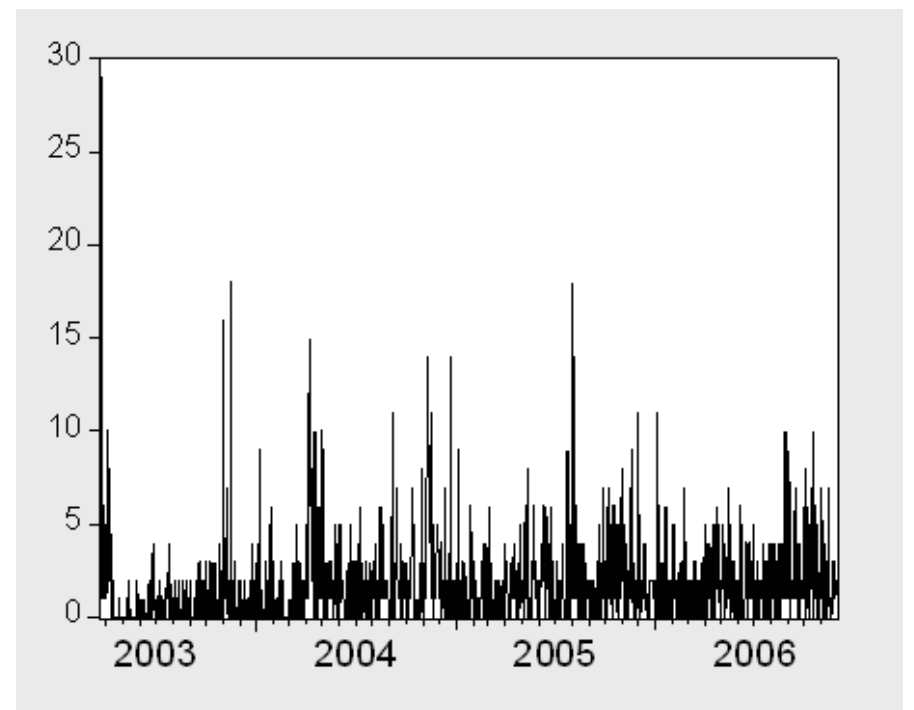

Figure 2: U.S. Soldiers Killed in Action, Daily (CENTCOM)

combat between insurgent and Coalition forces. Finally, $P$ denotes a probability operator and $E$ an expectations operator.

Theoretically, $C$ is known to Coalition forces, while $I$ is known to the insurgents. ${ }^{22}$ Our objective, then, is to identify changes in $I$ due to $C$. In order to do so, we use the data on Coalition operations as a proxy for $C$. However, as it is impossible to observe $P[$ Contact $\mid C, I]$ and $E[$ Casualties $\mid$ Contact $]$ (this data is not released because of operational security considerations), we must make assumptions in order to produce an estimate.

Implicit in the use of the casualties data as a proxy for the insurgents' response is that the lethality of attacks (represented in Eq. 1 by $P[$ Contact $\mid C, I]$ and $E[$ Casualties $\mid$ Contact $]$ ) has remained constant. However, if one assumes that increased recruitment helps the insurgency, an increase in the lethality of insurgent techniques is likely to be a function of recruitment as it would seem likely that the technology of the insurgency is a function of the strength of the overall insurgency. ${ }^{23}$

\footnotetext{
${ }^{22}$ Note that due to the decentralization of operational decisions on both sides, it is unlikely that these values are perfectly known even by their own side.

${ }^{23}$ One causal link would be the ability of the insurgency to recruit those with advanced technical skills.
} 


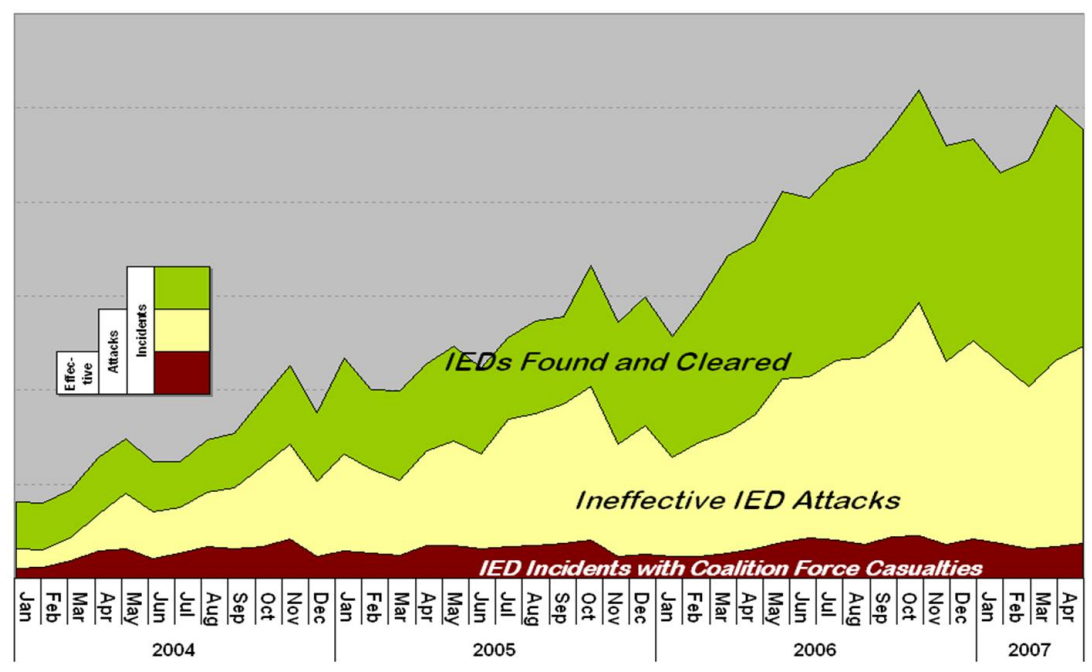

Figure 3: Casualty-Producing Attacks (JIEDDO)

Using a lethality correction, however, opens its own set of problems. For example, it may be possible to include a correction for lethality based on the number of soldiers killed per incident. Some limited lethality data is available from the U.S. Department of Defense's Joint IED-Defeat Organization (JIEDDO). JIEDDO was created to:

"... focus (lead, advocate, coordinate) all Department of Defense actions in support of the Combatant Commanders and their respective Joint Task Forces efforts to defeat Improvised Explosive Devices as weapons of strategic influence." 24

Figure 3 and Figure 4, which come from JIEDDO, both show that with the passage of time, insurgents require more attacks to produce any casualties. ${ }^{25}$

There are three difficulties with such a correction. First is that while JIEDDO has provided the graphs, they do not provide any information about the number of casualties produced per attack $(E[$ Casualties $\mid$ Contact $])$. Second, this correction produces bias in the presence of techniques

\footnotetext{
${ }^{24}$ Joint Improvised Explosive Device Defeat Organization (JIEDDO) Mission statement http://www.dtic.mil/whs/directives/corres/pdf/200019p.pdf

${ }^{25}$ The first graph can be found in a JIEDDO PowerPoint Presentation entitled "JIEDDO Cooperative Opportunities," available from the Department of Defense website http://www.acq.osd.mil/ic/. The second was reported on the Wired.com blog Danger Room at http://blog.wired.com/defense/2007/06/ied_defeat_grou.html.
} 


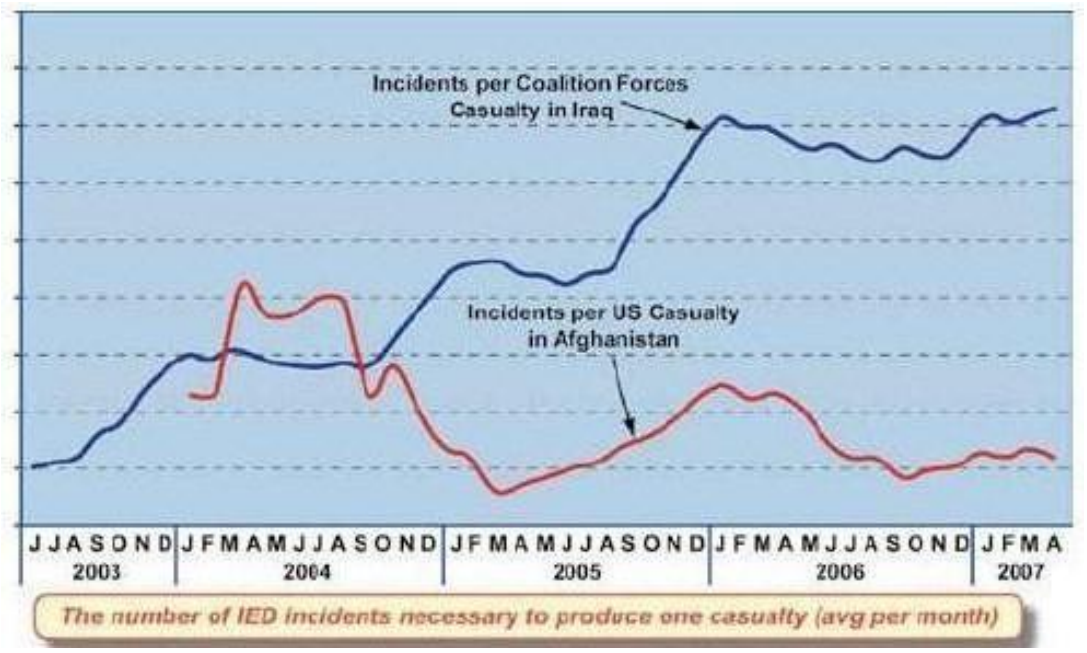

Figure 4: Incidents Per Casualty (JIEDDO)

that change the probability of killing at least one soldier (a change in $E[$ Casualties $\mid$ Contact $]$ ). For example, the use of explosively formed penetrator (EFP) IEDs, which first appeared in small amounts during the course of our sample, may both change lethality for incidents where at least one soldier is killed and change the probability that at least one soldier is killed. Finally, the statistic is biased in the presence of learning by the Coalition forces. ${ }^{26}$ Coalition learning appears to be occurring - a recent Department of Defense release states:

"While the incident rate of IED attacks has gone up, the casualty rates are actually declining, he said. In 2003, a servicemember had a 50-50 chance of dying in an IED attack, Votel said. That number has since decreased to about 18 percent, he said." ${ }^{27}$

In the end, as long as the lethality series is stationary and orthogonal to our other independent variables, the estimates of the parameters of those variables are unbiased.

A second limitation of the data is that it excludes other Coalition partner casualties and non-

\footnotetext{
${ }^{26}$ JIEDDO does not identify the factors in both insurgent and Coalition techniques, tactics and procedures that cause these changes. It is therefore impossible to identify changes in lethality due to actions of the insurgents, because variation due to Coalition learning is also present.

${ }^{27}$ http://www.defenselink.mil/news/newsarticle.aspx?id=31400
} 
military national casualties, e.g., contractors, reporters, etc. While icasualties.org does provide estimates for both of these, they are inconsistently reported, and unlike the U.S. casualty data, these counts are therefore not complete. ${ }^{28}$ Furthermore, it is virtually impossible to find any accurate data on the number of Iraqi civilians - another insurgent target - killed. These numbers may vary by an order of magnitude or more, and are therefore sufficiently unreliable that we do not consider them.

The exclusion of these casualties will likely bias the estimated impact of operations on Coalition casualties downward as insurgents have other targets available. In addition, there is some evidence that this bias is becoming more of a concern as the conflict continues. For example, Lawrence J. Korb, a former assistant secretary of defense for manpower during the Reagan administration recently stated: ${ }^{29}$

"The insurgents are going after the softest targets, and the contractors are softer targets than the military. The U.S. is being more aggressive over there, and these contractor deaths go right along with it."

Finally, for the present analysis we only incorporate a subset of this data. As was mentioned earlier, the characteristics of combat appear fundamentally different for the initial invasion stage and the post-invasion insurgency. Our focus is on the responses of the insurgency rather than the responses during the initial major combat operations. We also limited our analysis so as not include the two large-scale operations similar to conventional conflict, i.e., the battles of Fallujah in April and November 2004. These periods would fail to yield any additional observations in the operations series because they would not contain any of the flags - the outgrowth is that despite the sharp increase in Coalition activities during those periods, we do not see spikes on the Operations graph

\footnotetext{
${ }^{28}$ The icasualties.org data does provide estimates of non-U.S. Coalition soldiers killed in combat and of nonmilitary casualties. For example, as of May 31st, 2007, over icasualties.org 300 non-U.S. Coalition soldiers and 400 contractors have been killed.

${ }^{29}$ Death Toll for Contractors Reaches New High in Iraq - John M. Broder and James Risen - May 19th, 2007 New York Times: Front Page.
} 
corresponding to those months. We do, however, see large spikes in U.S. casualties. ${ }^{30}$ Also, we excluded the period prior to the U.S. Presidential election of 2004. One might suspect that much of the insurgents' activity would be directed at attempting to influence the outcome of the U.S. election rather than responding to actual Coalition activity. Similarly, Coalition commanders may have responded to political considerations (including a fear of seeming political by, for example, launching major operations immediately prior to the election) by changing levels of operations. We therefore begin our analysis on November 26th, $2004 .^{31}$ We conclude the analysis on November 31 , 2006 .

\section{Empirical Methodology and Results}

Our daily data is by definition count data. As has been highlighted in the literature, e.g. Wooldridge (2002), the application of ordinary least squares techniques (which do not account for the data being truncated at zero and the integer nature of the data) will produce biased and inconsistent estimates. ${ }^{32}$ In order to deal with the non-normality of the data we follow Enders and Sandler (2002) and aggregate our data temporally.

While Enders and Sandler (2002) aggregate their terrorist attack count data to yield quarterly values, our daily counts are summed to produce weekly counts. This transformation produced data which were no longer truncated at zero. Specifically, the minimum weekly value for the CENTCOM casualties data is (3), the maximum is (33), and its medium value is (12). The CENTCOM operations data produces (1) observation at (0) but returns a medium of (13) and a maximum of (56). Figure 5 and Figure 6 show the data.

As our data are time-series, before examining the relationship between the weekly data, we need

\footnotetext{
${ }^{30} \mathrm{An}$ alternative would be to use dummy variables to capture these outliers. This approach however produced qualitatively similar results.

${ }^{31}$ The United States Presidential election was held on November 2nd, 2004. The November 26th, 2004 date reflects the adjustment, given lags, to include only post-election data.

${ }^{32}$ Count data typically has a large amount of zeros or small values and is clearly discrete. In addition the data are all close to or within one standard deviation of the mean.
} 


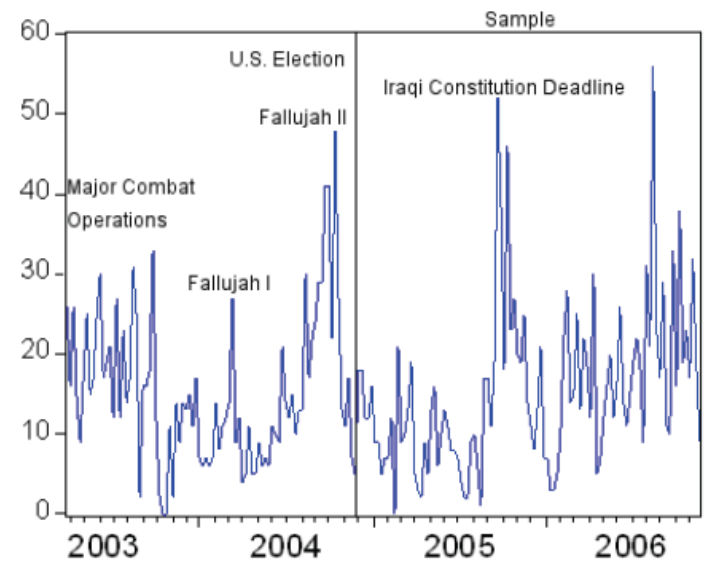

Figure 5: Coalition Operations, Weekly

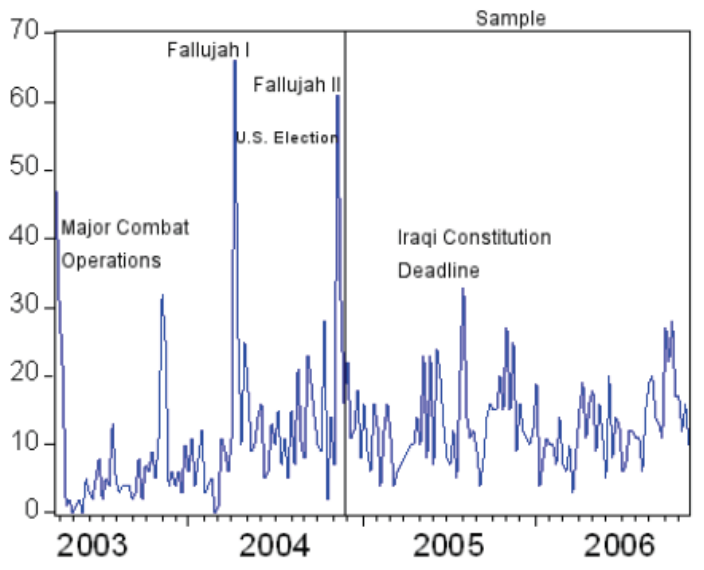

Figure 6: U.S. Soldiers Killed in Action, Weekly 
to examine whether the individual series have unit roots. This issue goes beyond the typical econometric concerns, it has direct policy implications: if the series are stationary, Coalition operations only have short-run effects on casualties. However, if the series are nonstationary, they will exhibit long memory. In both cases, it is important to determine the total effect of an exogenous increase in operations on casualties - and the implications of this effect are directly dependent on the stationarity of the series.

\begin{tabular}{|l|l|l|}
\hline Series & Daily & Weekly \\
\hline Operations & 0.000 & 0.001 \\
\hline Casualties & 0.000 & 0.000 \\
\hline
\end{tabular}

Table 2: $p$-values of Augmented Dickey-Fuller Tests for Stationarity - 11/26/2004 $12 / 01 / 2006$

Table 2 reports Augmented Dickey-Fuller (ADF) tests for nonstationarity for the data. ${ }^{33}$ For both the daily and weekly data, these tests reject the null hypothesis of nonstationarity for both series. ${ }^{34}$ Therefore, the following estimation incorporates our data in levels.

As was mentioned above, the weekly data allows us to use the traditional linear VAR model. Specifically, we model casualties $\left(K_{t}\right)$ and Operations $\left(O_{t}\right)$ as follows:

$$
\left(\begin{array}{c}
K_{t} \\
O_{t}
\end{array}\right)=\mathbf{A}_{0}+\mathbf{A}_{1}\left(\begin{array}{c}
K_{t-1} \\
O_{t-1}
\end{array}\right)+\ldots+\mathbf{A}_{j}\left(\begin{array}{c}
K_{t-j} \\
O_{t-j}
\end{array}\right)+\mathbf{B X}_{t}+\varepsilon_{t}
$$

where $\mathbf{A}_{0}$ is a vector of constants, $\mathbf{A}_{1}, \ldots, \mathbf{A}_{j}$ are the associated coefficient matrices for lags 1 , $\ldots, j$ and $\mathbf{B}$ is matrix containing coefficients for a vector of exogenous variables, $\mathbf{X}$. Within $\mathbf{X}$ we include a linear and a dummy variables for the week prior to the August 15th, 2005 deadline for the Iraqi Parliament to draft a new constitution. One could argue that insurgency action was more directed at influencing domestic agenda, at least as compared to other periods. ${ }^{35}$

\footnotetext{
${ }^{33}$ The tests included both constant and trend. We also tested down from a maximum lag order of 4 in all cases.

${ }^{34}$ Other tests, e.g., Elliott, Rothenberg and Stock (1996), produce similar results.

${ }^{35}$ During these two weeks, the level of United States casualties was 33 and 20, respectively. Moreover, the 33 causalities during the week prior to the draft deadline was the highest level incurred by the U.S. during the sample period, nearly $150 \%$ higher than average. Of the 105 observations that were used in the analysis only $10 \%$ were above 20 and only this observation was above 30 .
} 
An important choice in the above equation is the choice of lag, i.e., $j$. As both the Akaike Information Criterion and Final Prediction Criteria choose a lag of (3) and given that more lags produce qualitatively similar results, we incorporate the more parsimonious (3) lags. ${ }^{36}$ The choice is also consistent with the assumption that any possible recruitment effects would require a period of time to show up. Recruitment requires the individual to make the decision to join, be trained and finally be deployed before our measure would pick it up.

\begin{tabular}{|c|c|c|}
\hline & Casualties $_{t}$ & Operations $_{t}$ \\
\hline Casualties $_{t-1}$ & $\begin{array}{c}0.011 \\
(0.091)\end{array}$ & $\begin{array}{l}-0.031 \\
(0.161)\end{array}$ \\
\hline Casualties $_{t-2}$ & $\begin{array}{c}\mathbf{0 . 1 8 0}^{* * *} \\
(0.071)\end{array}$ & $\begin{array}{l}-0.140 \\
(0.126)\end{array}$ \\
\hline Casualties $_{t-3}$ & $\begin{array}{c}0.064 \\
(0.068)\end{array}$ & $\begin{array}{c}0.072 \\
(0.119)\end{array}$ \\
\hline Operations $s_{t-1}$ & $\begin{array}{l}\mathbf{0 . 0 9 6}^{*} \\
(0.057)\end{array}$ & $\begin{array}{c}\mathbf{0 . 1 7 4}^{* *} \\
(0.101)\end{array}$ \\
\hline Operations $_{t-2}$ & $\begin{array}{c}0.019 \\
(0.058)\end{array}$ & $\begin{array}{c}\mathbf{0 . 1 9 4}^{* *} \\
(0.10242)\end{array}$ \\
\hline Operations $_{t-3}$ & $\begin{array}{c}\mathbf{0 . 1 2 3}^{* * *} \\
(0.058)\end{array}$ & $\begin{array}{c}\mathbf{0 . 1 8 3} * * \\
(0.103)\end{array}$ \\
\hline Constant & $\begin{array}{c}\mathbf{5 . 8 4 6}^{* * *} \\
(1.733)\end{array}$ & $\begin{array}{c}5.385 \\
(3.055)\end{array}$ \\
\hline$T$ & $\begin{array}{c}-0.005 \\
(0.019)\end{array}$ & $\begin{array}{l}\mathbf{0 . 0 5 7} \text { * } \\
(0.034)\end{array}$ \\
\hline$D(08 / 05 / 2005)$ & $\begin{array}{c}24.279 * * * \\
(5.301)\end{array}$ & $\begin{array}{c}0.692 \\
(9.343) \\
\end{array}$ \\
\hline$R^{2}$ & 0.306 & 0.285 \\
\hline$F-$ statistic & 5.297 & 4.784 \\
\hline Log-likelihood & -315.291 & -374.801 \\
\hline
\end{tabular}

Table 3: Vector Autoregressive Estimates for Operations and Casualties, Weekly $(11 / 26 / 2004-12 / 01 / 2006)$

Table 3 reports the estimated coefficients. ${ }^{37}$ In general, the estimates suggest a relatively strong

\footnotetext{
${ }^{36}$ The Schwartz Information Criterion did, however, suggest the use of (0) lags. In what follows, the impulse response functions are sensitive to the choice of (0) lag or (3), but are robust to more lags. One concern is that if we do not include enough lags, the associated errors will not be white noise processes and will bias our results. All in all, the choice of $p=3$ would seem the more appropriate lag length for the model.

${ }^{37}$ Both LM tests for autocorrelation and White's tests for heteroskedasticity suggested that the error terms were
} 
impact on future Coalition causalities from changes in Coalition operations. Specifically, an additional Coalition operation increases the likelihood of a Coalition soldier being killed by 0.123 three weeks out. ${ }^{38}$ In contrast, there appears to be little response of operations to increased Coalition casualties.

We also performed Granger-causality tests (Granger (1969)) to examine the direction of causality. Table 4 reports Granger-causality tests for the two series. Not surprisingly, the results suggest that while Coalition operations do Granger-cause Coalition casualties, additional Coalition causalities do not Granger-cause Coalition operations.

\begin{tabular}{|c|c|c|}
\hline$H_{0}$ & $\chi^{2}$ & $p$-value \\
\hline Operations does not Granger-cause Casualties & 11.137 & 0.011 \\
\hline Casualties does not Granger-cause Operations & 1.676 & 0.642 \\
\hline
\end{tabular}

Table 4: Granger-Causality Tests, 11/26/2004 - 12/01/2006

Perhaps a better way to view the impact is to examine the associated impulse response functions. Figure 7 and Figure 8 report the estimated impulse response functions (IRF) which are an outgrowth of the estimates of Table 3. The accumulated IRF were obtained without factorization, i.e., we ignore any possible correlations in the VAR residuals. ${ }^{39}$

The $95 \%$ confidence intervals were computed using asymptotic estimates of the standard errors. ${ }^{40}$ As before, these figures in tandem suggest that increased Coalition activity increases the number of Coalition casualties. The converse, however, does not appear to occur - increased Coalition casualties do not seem to increase Coalition activity.

Specifically, Figure 7 suggests that additional Coalition activity produces little initial response. well specified.

${ }^{38}$ The first lag was often significant depending upon sample. The third lag, however, was not sensitive to the sample chosen.

${ }^{39}$ We also examined the accumulated impulse response functions obtained when a Cholesky-type decomposition was done and using Pesaran and Shin (1998) generalized impulse response functions. For the Cholesky-type, the ordering of the series did not change any of the results and in all of these cases, the results were entirely consistent with the results presented in the paper. The similarity in all of these impulse response functions suggests that there is little correlation between the VAR estimate errors (Enders 1995).

${ }^{40}$ Monte Carlo estimates - of up to 10,000 replications - of the associated standard errors produced similar results. 
Accumulated Response of KIA to Nonfactorized One Unit OPS Innovation

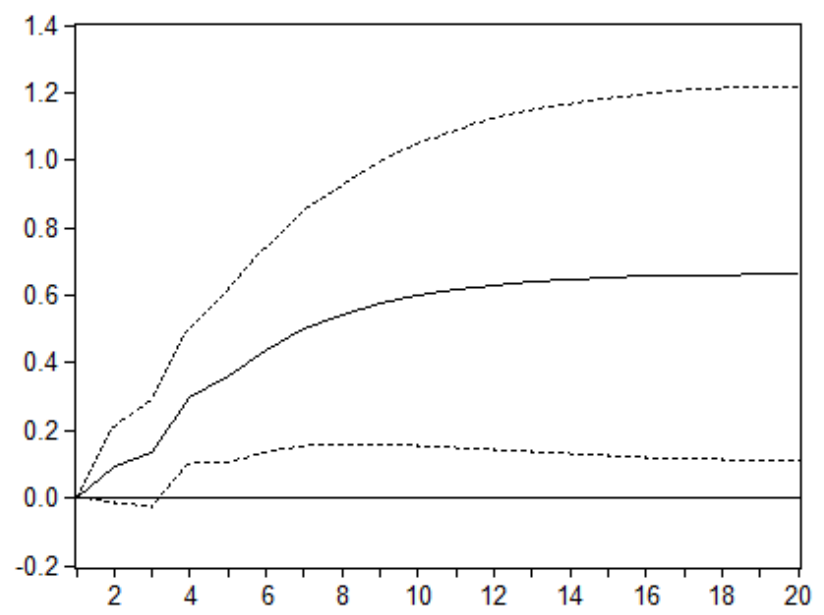

Figure 7: Response of Casualties to Operations - 11/26/2004 - 12/01/2006

Accumulated Response of OPS to Nonfactorized One Unit KIA Innovation

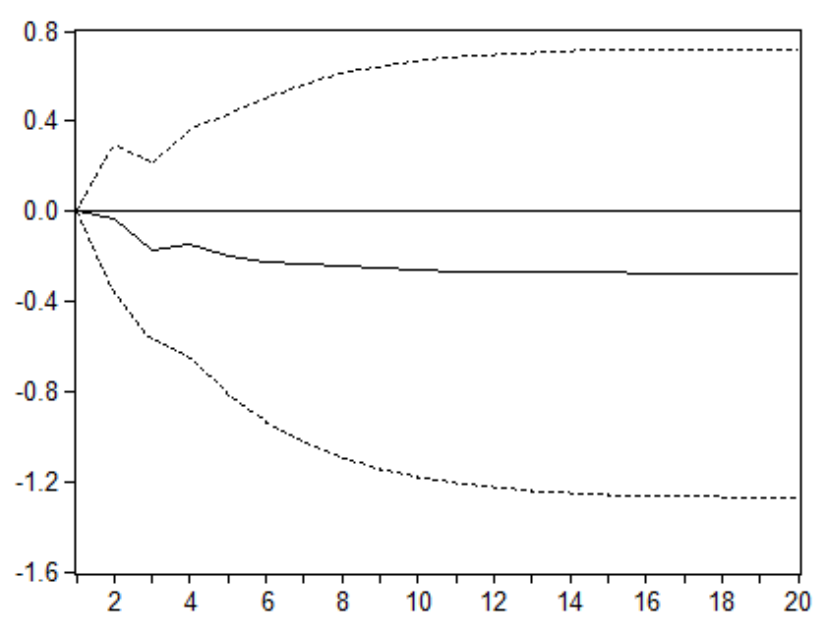

Figure 8: Response of Operations to Casualties - 11/26/2004 - 12/01/2006 
However, as time passes the impact begins to rise with a significant rise in the costs at about 3 weeks. At this point Coalition casualties rise significantly. At 10 weeks out, the response has leveled off to a cost of slightly above 0.5 Coalition casualties per week. In contrast, Figure 8 suggests that there is little response on the part of Coalition operations to an additional Coalition casualty.

The usual econometric concern of temporal stability exits. We therefore estimated rolling versions of Equation (1) to produce rolling time series of estimates of the associated impulse response functions. Our choice of a rolling regression approach reflected a compromise between two competing interests. On one side we have a desire to incorporate enough information to capture the underlying relationships. However, these underlying relationships may change over time and we desire to mark possible changes in these responses. Our concern was then that the traditional approach would mute the actual changing points. We therefore chose a window which was moderately long (one year) and extended these out to two years. The effect of this experiment was negligible.

We chose an initial window (sample size) of 80 . As our data sample extends from 11/26/0412/01/06, the initial estimation period for Equation (1) was therefore 11/26/04-06/02/05. We then estimated the associated accumulated IRF over a 80 week horizon. In addition, $95 \%$ confidence intervals for the responses were computed. The starting and ending dates were, then, adjusted forward by one period and Equation (1) was re-estimated and the associated IRF and $95 \%$ confidence intervals were re-computed. The process was continued throughout the entire sample to produce a time series of estimates ranging from 04/08/2005 - 12/01/06.

Figure 9 and Figure 10 reports the result of our rolling estimates. Specifically, the Figures show the 10th week accumulated IRF for each series. The two Figures highlight the fact that the responses appear to be highly stable over our sample. For example, the maximum impact that Coalition operations have on Coalition casualties is (0.646) while the least impact is (0.499). In addition, all of the responses are significant. Finally, the lack of Coalition response to Coalition 


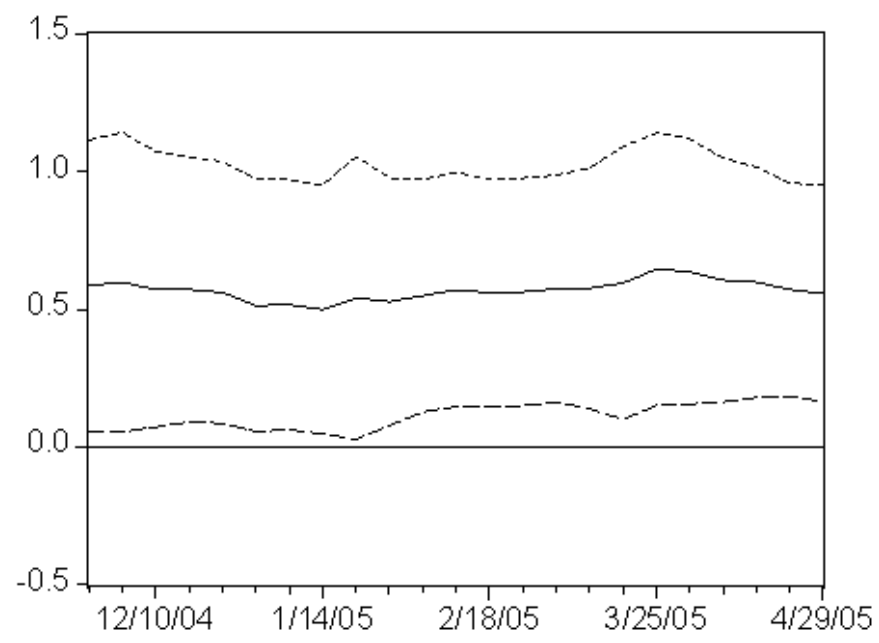

Figure 9: 10th Week Response of Casualties to Operations

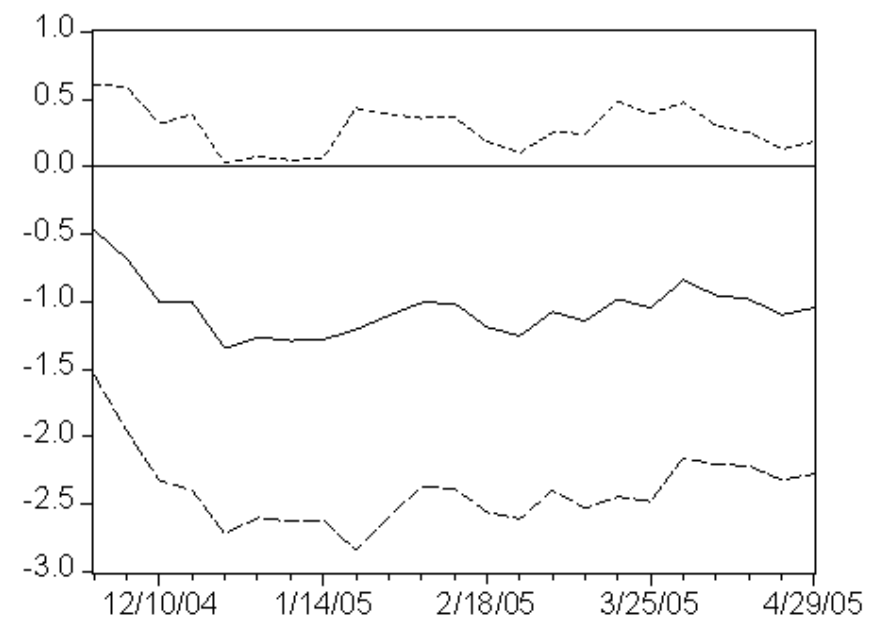

Figure 10: 10th Week Response of Operations to Casualties 
casualties persists. While the actual response does vary a bit across the estimates, it is never significant.

Overall, then, the total effect of additional operations conducted by the Coalition is to increase in the number of future soldiers killed in action. This effect is independent of the increase due to a higher level of operations (more soldiers in harm's way leads to more casualties) because of the exogeneity of the lagged values. These findings are generally robust to both different methodologies and to different levels of aggregation (daily or weekly).

\section{Discussion}

Interpretation of the positive association between Coalition operations and future Coalition casualties combined with the Granger noncausality of casualties to operations may come from several avenues. We, therefore, consider three possible explanations for the above results, which we term the retiming hypothesis, the reverse causality hypothesis, and the recruitment hypothesis.

\section{$5.1 \quad$ Retiming}

The first hypothesis, that insurgents may retime their attacks, may suggest that some insurgent groups attempt to differentiate themselves from other groups by timing their attacks to retaliate to specific Coalition operations. This argument depends in part on how easily the insurgents can substitute across space in carrying out their attacks. If we assume, for example, that insurgents can carry out exactly $N$ attacks per week. Insurgents, in principle, may choose the location of their $N$ attacks based on a desire to retailate/show strength in the same areas in which coalition operations were recently conducted or for any other reason.

However, if this explanation is responsible for the entire effect, one would expect to see a period of relative safety, leading to zero net effect. Unless the insurgents are gaining equipment or personnel due to Coalition operations, their capability to carry out attacks would be unaffected by Coalition 
operations. ${ }^{41}$ Assuming that insurgents are optimizing their expenditures of personnel and equipment (as found in Benmelech and Berrebi (2007) for Palestinian suicide bombers), shifting the time of attack would reduce their overall efficiency. The observed impulse response functions would seem to rule out this out as an possibility.

\subsection{Reverse Causality}

A second possible explanation revolves around the reverse causality hypothesis. This hypothesis argues that Coalition offensive operations are conducted in anticipation of higher future casualties, i.e., Coalition forces gain intelligence which indicates an upcoming insurgent attack. Obviously expectations about the future exist in this setting; every Coalition unit deals with intelligence on a routine basis. A positive response of casualties to operations would appear, then, because a higher level of operations mitigates future Coalition casualties. However, since information is incomplete the Coalition forces cannot completely eliminate future casualties.

An implication of the reverse causality hypothesis is that Coalition operations reduce the ability of the insurgent to wage a planned counterattack. The reduced ability is likely an outgrowth of operations which remove resources from the insurgent arsenal. In order to assess whether the evidence supports the reverse causality hypotheses, we split up operations into four subgroups: CACHEONLY, DETAINONLY, CACHEDETAIN, and NOCACHEDETAIN. Specifically, we grouped operations where a cache was found into CACHEONLY, where insurgents were detained into DETAINONLY, where both a weapons cache was found and an insurgent was detained into CACHEDETAIN, and where neither a weapons cache was found nor where insurgents detained into NOCACHEDETAIN. ${ }^{42}$ Summary statistics for these series are presented in 5 .

\footnotetext{
${ }^{41}$ It is possible that insurgents gain information on Coalition techniques, tactics, and procedures (TTPs). However, it seems unlikely that the marginal increases in information are significant, as the TTPs do not vary with the number of operations conducted, and therefore the insurgents learn almost as much from observing one Coalition operation as they do from observing many.

${ }^{42}$ We generate DETAINONLY using nab, capture, and detain, CACHEONLY using cache, CACHEDETAIN as operations with both these terms, and NOCACHEDETAIN as all other operations. All operations are partitioned into one of these sets, and no operation may belong to more than one set.
} 


\begin{tabular}{|l|l|l|l|}
\hline Series & $\boldsymbol{t}$ & Mean & Std. Dev. \\
\hline \hline KIA & 105 & 12.923 & 5.900 \\
\hline CACHEONLY & 105 & 1.663 & 1.929 \\
\hline DETAINONLY & 105 & 1.865 & 2.2315 \\
\hline CACHEDETAIN & 105 & 2.163 & 2.150 \\
\hline NOCACHEDETAIN & 105 & 14.154 & 10.301 \\
\hline
\end{tabular}

Table 5: Summary Statistics for Weekly Counts, 11/26/04 - 12/01/06.

We then followed our earlier approach and estimated a five-equation VAR with KIA and the four operations variables as endogenous variables. The accumulated KIA responses are reported in Figure 11. Two resources which would seem at the heart of insurgents ability to wage attacks on Coalition forces are weapons cache and the insurgents themselves. Interestingly while the specific response of KIA to DETAINONLY is positive, its response to CACHEONLY is negative. ${ }^{43}$ When one combines operations which find both a weapons cache and detain an individual, i.e., CACHEDETAIN, the response of KIA lies above both the responses to CACHEONLY and DETAINONLY. The NOCACHEDETAIN operations appear most similar to those presented in Figure 7. Moreover, while each responses' associated $95 \%$ confidence intervals are omitted from 11 only the response of KIA to NOCACHEDETAIN. None of the remaining three responses are statistically significant.

While the finding of weapons cache and detaining suspected insurgents does not return significant responses, their parameter estimates may still be informative. If one accepts that the insurgents are, broadly, constrained by the amount of equipment they have available (explosives, detonators, rifles, ammunition) and the personnel available to make use of it. Further given the large quantities of munitions that have gone missing and are assumed to have fallen into the hands of the insurgents and the relatively small quantities found during Coalition operations, one may make the assumption that the insurgency is more disrupted by negative shocks to its labor force (the killing, wounding,

\footnotetext{
${ }^{43}$ In order to check for the possibility of correlations between the CACHEONLY, DETAINONLY, and CACHEDETAIN series, a Cholesky-type impulse with multiple orderings were also used. However, reordering in the Cholesky-type impulse does not significantly change the results in Figure 11. Furthermore, the results are also qualitatively similar if a generalized impulse as in Pesaran and Shin (1998) is used.
} 


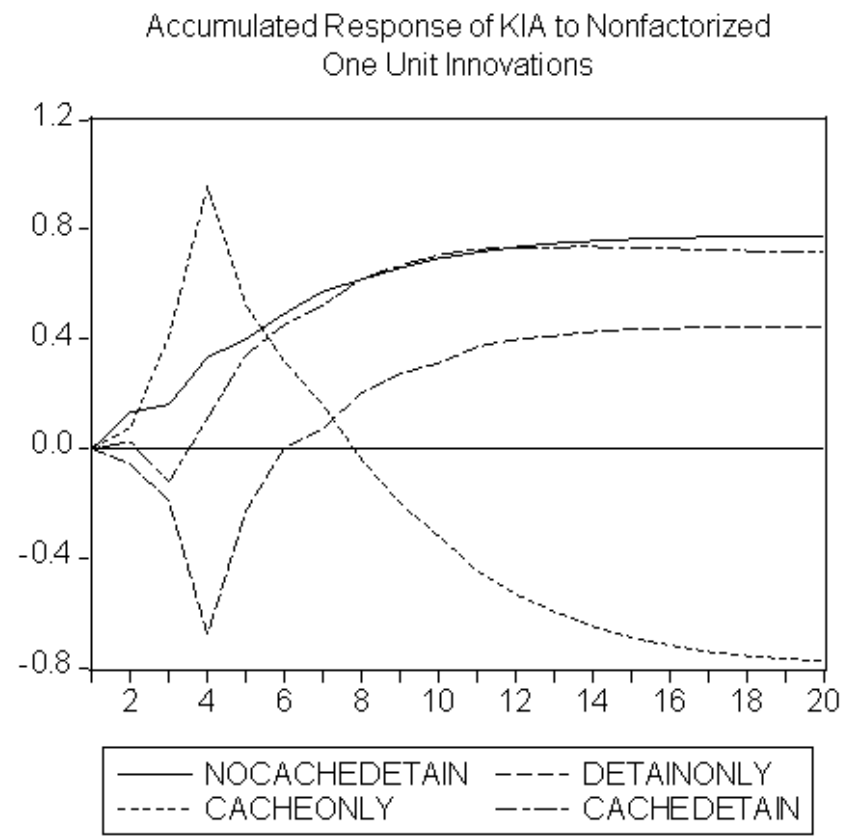

Figure 11: KIA Responses in Five-Equation VAR

or detention of insurgents) than to its capital stock (the finding of weapons caches). In which case, we should expect the negative KIA response to DETAINONLY be greater (in magnitude) than to CACHEONLY under the reverse causality hypothesis (since a positive shock to DETAINONLY represents a negative shock to the insurgent labor force, and a positive shock to CACHEONLY represents a negative shock to the insurgent capital stock). Figure 11 finds just the opposite.

Finally, the relationship between the response of Coalition causalities to CACHEONLY and CACHEDETAIN also raises doubts with respect to reverse causality. Since the difference between these two types of operations is in the detention (since both types of operations find a cache), and the probability of detaining given that an operation is conducted is assumed to be out of control of the Coalition forces (they are assumed to always maximize this probability, given that an operation is conducted), these two responses test a difference that cannot be explained by reverse causality since it is exogenous with respect to Coalition operations. 


\subsection{Recruitment}

The third possible explanation for the estimated rise in Coalition Casualties in response to increased Coalition operations is that these operations increase recruitment. As reported in FM 7-10: The Infantry Rifle Company (2000, Section A-13: Cordon and Search Operations):

A basic principle when searching a built-up area is to limit the inconvenience to the population. They should be inconvenienced to the point where insurgents and sympathizers are discouraged from remaining in the locale, but not to the point that they collaborate with the enemy as a result of the search.

Offensive counterinsurgency operations may have both benefits and costs. A possible cost is that it will increase the number of recruits that insurgents are able to obtain and thereby increase the costs in terms of soldiers' lives. Rosendorff and Sandler (2004), for example, differentiate between two types of countermeasures taken to thwart a terrorist's threat: defensive and proactive (offensive) countermeasures. Defensive countermeasures are actions which are undertaken to "deflect the intended attack to a softer target...(Rosendorff and Sandler 2004, p. 657)" In contrast, proactive countermeasures are actions "which involve direct strikes against a terrorist group or its assets (Rosendorff and Sandler 2004, p. 658)."

Proactive countermeasures may produce divergent outcomes. The most obvious, and the desired response on the part of the State, is to weaken the ability of the terrorist group to respond and to ultimately end the group's activities. A second effect, however, is the possibility that the measure may be seen as unprovoked, unwarranted, or in some way inappropriate. ${ }^{44}$ These actions may actually increase the terrorist's ability to wage war by increasing sympathy for the terrorist. Such increased sympathy would embolden the terrorist and possibly strengthen her through increased recruitment. Rosendorff and Sandler also find that the recruitment effect increases the probability

\footnotetext{
${ }^{44}$ These operations need not actually have any of these characteristics, but merely be perceived as such.
} 
of spectacular attacks - those with high death tolls or of a symbolic nature.

Using a game-theoretic model, Rosendorff and Sandler find that in the absence of a recruitment effect, the State, through the use of enough force, is able to eliminate terrorists' spectacular responses. In this case, the State need only worry about its ability to diminish the terrorists' current ability to wage counterattacks. This is not the case if proactive countermeasures produce a recruitment effect. With recruitment, not only must the State continue to concern itself with diminishing the terrorists current ability but must now also concern itself with the impact that recruitment may have on the terrorist's future ability to wage counterattacks. In addition, as the existence of recruitment increases the benefits from a successful counterattack, the State must also deal with an increase in the likelihood of a terrorist's spectacular response.

It is possible that Coalition proactive operations are viewed by those on the periphery as unwarranted or unacceptable. These operations may thus entice some to join the insurgent cause. The increased recruitment, in turn, would increase the ability of the insurgency to attack the Coalition. The rise in attacks would then manifest themselves in increased Coalition casualties.

Finally, while the results from the two-equation and five-equation VARs suggest that retiming and reverse causality cannot explain the full set of results, they do suggest a significant recruitment effect. Operations where the Coalition does not detain anyone or find a cache are the least likely to be perceived as justified, and therefore lead to the largest recruitment effect. We find that these operations produce the highest response in KIA of all the series. Similarly, detections without the presence of a cache are likely to make residents believe that the people detained were not insurgents, and therefore increase the recruitment effect. These results are not statistically significant (likely due to the low amount of efficiency afforded by limited reporting of Coalition operations), but they do present an argument for a recruitment effect. ${ }^{45}$

\footnotetext{
${ }^{45}$ See 3.1 for a discussion of reporting standards.
} 


\subsection{Operations}

Another result from the above analysis is that Coalition operations do not appear to be impacted by its level of casualties. Therefore, while the insurgents change their level of operations in response to the Coalition, the Coalition does not change its level of operations in response to the insurgents. ${ }^{46}$ This finding may suggest that Coalition operations are conducted on a schedule-basis rather than in a systematic response to insurgent activity. ${ }^{47}$ After all the goals of the Coalition and the insurgents are very different. If these operations are routine patrols or cordon and search of an area based on suspicion rather than good intelligence, these are operations that are likely to yield the lowest benefit and the highest cost. The fact that Coalition operations do not respond to Coalition casualties suggests that these operations represent the bulk of the operations conducted, and provide an explanation for the prevalence of the recruitment effect.

Furthermore, the non-responsiveness of operations to casualties may suggest that Coalition operations today cannot effectively isolate the perpetrators of yesterday's attacks. While the costs of being an insurgent are shared among all insurgent groups,the benefits to insurgent groups from carrying out an attack are largely localized to that group. As an example, imagine that there are $n$ insurgent groups of equal size. While there are some externalities in terms of the common goal among all insurgents of destroying the Coalition, we can assume that local civilians who may be considering joining an insurgent group can tell which groups carry out which attacks. Therefore the group carrying out an attack derives all the benefits from it but only suffers $1 / n$ of the costs from the resulting proactive countermeasures by the Coalition. This externality will lead to oversupplying of attacks.

\footnotetext{
${ }^{46}$ At least not in ways which would be captured by our measure.

${ }^{47}$ The schedule-basis theory provides a further explanation for these results regarding incentives: Assuming that the effects are large enough to be noticed by commanders, why do they not set operations at an optimal level? It is likely that the incentives for commanders are misaligned - higher commanders may be demanding action in an attempt to solve the problem.
} 


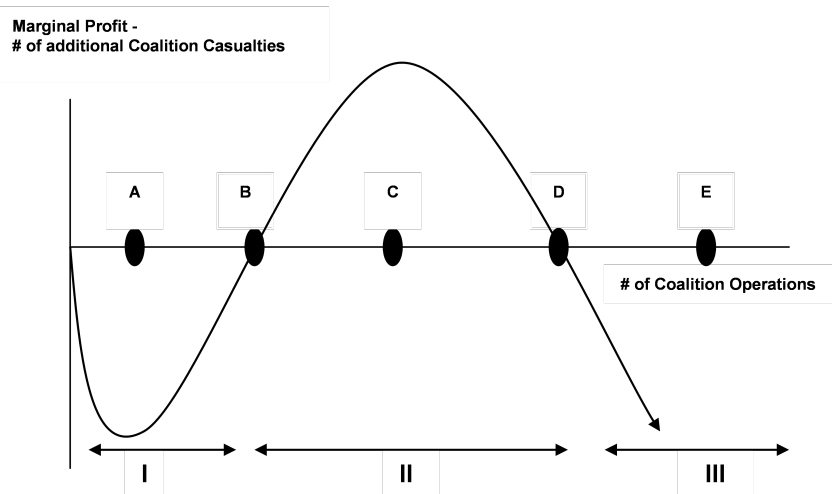

Figure 12: Marginal Benefit of Increased Coalition Operations

\subsection{The optimal level of operations}

A final note on the implications of the above results - in the range of operations seen, more operations are not necessarily better. As was mentioned in the introduction, Coalition offensive operations have two possible impacts - reducing the insurgent's ability to wage counterattacks and increasing recruitment. When the Coalition forces choose few operations they are able to focus on those operations that are the most likely to have significant effects on reducing the insurgents' ability to counteract, i.e., reducing the loss of Coalition lives. In addition, as the Coalition forces are doing fewer operations, the likelihood of recruitment will be small. However there exist diminishing marginal returns to operations - due to poorer intelligence - as the number of operations increases. At the same time, the likelihood of recruitment will rise as the Coalition forces come more in contact with the general public. Finally, there must be a level of operations where operations begin to overwhelm the insurgency.

Figure 12 highlights this relationship. When the scale of operations is small, i.e., region $\mathbf{I}$, the return in terms of a reduction in the loss of Coalition forces' lives is large. However, as the scale of operations increase, the cost due to recruitment rises and the potential gain from these operations 
diminishes, i.e., region II. Finally, there exists a point at which the Coalition force operations are so large that they completely diminish the insurgent's ability to counterattack and recruitment effects are proportionally small, i.e., region III.

Our results suggest that the Coalition is presently in region II. If for example, the current level of operations is between points $\mathbf{B}$ and $\mathbf{D}$, a rise in the number of operations will be associated with increased casualties, as it will be throughout region II. In this case, the Coalition force has two options: (1) reduce operations to a level in region $\mathbf{I}$ and obtain point $\mathbf{B}$ or (2) increase operations to a level of operations in region III. ${ }^{48}$ However, if this is impossible, region II point $\mathbf{B}$ would be preferred. ${ }^{49}$ Assuming constant troop levels, reduced operational tempo frees up Coalition assets for seeking a qualitative change that would bring victory. These assets could, for example, be used for major combat operations against insurgent strongholds, training of Iraqi security forces or defensive protection of key sites.

\section{Conclusion}

In this paper, we investigate the response of the insurgency in Iraq to a subset of Coalition offensive operations. Specifically, we focus on the impact that proactive countermeasures, excluding major combat operations, have on the insurgency. We measure the Coalition operations through CENTCOM press releases and the insurgent's response through Coalition casualty reports. We then examined the dynamic relationship between the two within a multivariate VAR and the associated impulse response functions.

We find that two additional Coalition offensive operations lead to one more U.S. soldier killed in action. Using Granger causality tests, we further find that the insurgency reacts to changes in Coalition operations, but that the Coalition does not react to changes in the insurgency.

\footnotetext{
${ }^{48}$ It is important to note that at no point in our data set has the overwhelming side of this curve been observed.

${ }^{49} \mathrm{It}$ is also important to note that our assessment of policy impacts does not take into account benefits that cannot be measured in future casualties to the Coalition, such as Iraqi civilian casualties. If future Coalition casualties is not an appropriate proxy for these benefits, policy conclusions may differ significantly.
} 


\section{References}

Benmelech, Efraim and Claude Berrebi, "Attack Assignments in Terror Organizations and the Productivity of Suicide Bombers," 2007. NBER Working Paper No. W12910.

Blandford, Nicholas, "Attacks Turning to US Allies in Iraq," Christian Science Monitor, 1 December 2003.

Cauley, Jon and Eric I. Im, "Intervention Policy Analysis of Skyjackings and Other Terrorist Incidents," American Economic Review, May 1988, 78 (2), 27-31.

Elliott, Graham, Thomas J. Rothenberg, and James H. Stock, "Efficient Tests for an Autoregressive Unit Root," Econometrica, 1996, 64, 813-836.

Enders, Walter, Applied Econometric Time Series, New York, NY: John Wiley \& Sons, Inc., 1995. and Todd Sandler, "The Effectiveness of Antiterrorism Policies: A Vector-AutoregressionIntervention Analysis," American Political Science Review, December 1993, 87 (4), 829-844. and ___ , "Patterns of Transnational Terrorism, 1970-99: Alternative Time Series Estimates," International Studies Quarterly, 2002, 46, 145-165. and _ _ The Political Economy of Terrorism, Cambridge: Cambridge University Press, 2006.

, _ _ and Jon Cauley, "Causality Between Transnational Terrorism and Tourism: The Case of Spain," Terrorism, January 1991, pp. 49-58.

FM 3-0: Operations, Washington, DC: Headquarters, Department of the Army, 2001.

FM 7-10: The Infantry Rifle Company, Washington, DC: Headquarters, Department of the Army, 2000. 
Granger, C. W. J., "Investigating Causal Relationships by Econometric Methods and CrossSpectoral Methods," Econometrica, 1969, 37 (3), 424-438.

Hashim, Ahmed, Insurgency and Counterinsurgency in Iraq, Ithaca, New York, USA: Cornell University Press, 2006.

Jaeger, David A. and M. Daniele Paserman, "The Cycle of Violence? An Empirical Analysis of the Faltalites in the Palestianian-Israeli Conflict," November 2006. Working Paper.

and __ , "Israel, the Palestinian Factions, and the Cycle of Violence," American Economic Review Papers and Proceedings, 2006, 96 (2), 45-49.

Landes, William M., "An Economic Study of U.S. Aircraft Hijacking, 1961-1976," Journal of Law and Economics, 1978, 21, 1-31.

Leites, Nathan and Charles Wolf, Rebellion and Authority: An Analytic Essay on Insurgent Conflicts, Markham Publishing Company, 1970.

Pesaran, M. Hashem and Yongcheol Shin, "Generalized Impulse Response Analysis in Linear Multivariate Models," Economics Letters, 1998, 58 (1), 17-29.

Petraeus, David H. and James F. Amos, FM 3-24: Counterinsurgency, Washington, DC: Headquarters, Department of the Army, 2006.

Rosendorff, B. Peter and Todd Sandler, "Too Much of a Good Thing? The Proactive Response Dilemma," Journal of Conflict Resolution, October 2004, 48 (5), 657-671.

Sandler, Todd and Walter Enders, "An Economic Perspective on Transnational Terrorism," European Journal of Political Economy, 2002.

Schelling, Thomas C., The Strategy of Conflict, Harvard University Press, 1960. 
Wooldridge, Jeffrey M., Econometric Analysis of Cross Section and Panel Data, Cambridge, MA: MIT Press, 2002. 